\title{
The complexity of the antecedents influencing accountability in organisations
}

\author{
Hayley Pearson and Margaret Sutherland \\ Gordon Institute of Business Science, University of Pretoria, Sandton, South Africa
}

\begin{abstract}
Purpose Business, society and academic literature all show an increase in the demand for greater accountability. Although accountability is deemed to be central to performance in the workplace, it is an ever-expanding, complex and elusive phenomenon. There is very little empirical research in human resource literature on accountability's wide-ranging antecedents and how they are best implemented. This study set out to identify which factors have the greatest influence when holding an individual to account.

Design/methodology/approach Qualitative, exploratory research methods were adopted. Twenty semi-structured, in-depth interviews were conducted with CEO's, executives, human resource experts, senior managers and consultants in eight industries in South Africa. The data was analysed by thematic content analysis.

Findings The findings identified five dominant antecedents that are required to effectively hold an individual to account for their performance. These are the culture and leadership of the organisation, the systems in the organisation, the values and recruitment means of the individual and the clarity of role. For each of these factors, the key management mechanisms were identified.
\end{abstract}

Originality/Value A 'System of Accountability' model was developed depicting the interdependence of the factors and conceptualising a process that can be followed for human resource professionals to develop a culture of accountability. No equivalent integrated model could be found in the literature

Keywords Accountability, Management, Responsibility, Performance Management Paper Type Empirical research

\section{INTRODUCTION}

The issue of accountability is continuously being raised in organisations, government sectors and civil society. Mansouri \& Rowney (2014, p. 45) state that ensuring accountability is of "strategic importance" and Romzek (2015, p. 27) stresses that accountability is "fundamental to how people and organisations operate". What is evident is that there appears to be a need for greater accountability with increasing expectations being placed on it and further mechanisms required to support it (Patterson, 2013; Mero, Guidice \& Werner, 2012; Hall \& Ferris, 2011; Joannides, 2012; Mansouri \& Rowney, 2014; Busuioc \& Lodge, 2016; Brennan \& Kirwan (2016). The idea of accountability has developed from a restrictive form of financial 
and management accounting, to a more inclusive concept that takes on multiple forms and is driven by a variety of factors (Mero et al., 2012; Messner, 2009; Sinclair, 1995; Roberts, 1991). The need for employees to be held to account for good performance is widely accepted with Frink \& Klimoski $(2004$, p. 2) describing accountability as being the "root of a viable social system". Recently, a strong link between performance, behaviour and accountability has been established (Patterson, 2013; Mero et al., 2012; Frink \& Klimoski, 2004). However, according to recent research, increased pressure for accountability does not necessarily lead to improvement in an individual being held to account (Mansouri \& Rowney, 2014). Mero et al. (2012) question how a concept, which is fundamental to organisation success, is so under-researched.

Different types of accountability occur on multiple levels supported by varying relationships, all played out within a particular and open system. Busuioc \& Lodge (2016, p X) place particular emphasis on the varying degrees of "interest, intensity and investments" when considering such relationships. Romzek $(2015$, p. 29) refers to the complexity of accountability insisting that "accountability is not a puzzle or a formula to be solved" but rather "is a complex dynamic to be managed at best". Navigation through the complexity of this phenomenon is therefore, of particular importance (Mero et al., 2012; Tenbensel, Dwyer \& Lavoie, 2014; McKernan, 2012; Romzek, 2015). Hall, Frink \& Buckley (2015) in their review of the theoretical and empirical research of accountability explicitly identify a gap in the literature, saying "the extent to which actual employees prioritize accountabilities to different sources has received scant research attention". They stress the lack of empirical research available on the "antecedents to accountability" and the need for a better understanding of the links between the necessary antecedents, the sources of accountability and the relationships that exist within a system of accountability. Furthermore, it is worth noting that significant attention has been placed on the critic of accountability in Government and Governmental organisations in South Africa but little focus has been paid to the private sector and business operating in the country (The World Bank, 2011).

Significant emphasis is often placed on the monitoring of individuals by managers or systems in order to ensure accountability (Mero et al., 2012; McKernan, 2012; Joannides, 2012; Hall \& Ferris, 2011; Zelnik, Maletič, Maletič \& Gomišček, 2012). However, if explicit monitoring is removed, accountability to peers and oneself may also hold employees to account (Mero et al., 2012; Hall \& Ferris, 2011). Research is needed to identify which of these factors has a greater influence on accountability (Hall \& Ferris, 2011; Hall et al., 2015). This research seeks to establish the main drivers of accountability which enable organisations to improve performance of their employees. Furthermore, it is understood that 
accountability is encouraged through the use of specific mechanisms (Hall \& Ferris, 2011; Frink \& Klimoski, 2004). This study also aims to understand how the mechanisms support the main antecedents.

\section{LITERATURE REVIEW}

There are multiple definitions of accountability. The complexity of the construct ensures that it often is difficult to implement and a challenge to effectively measure (Bovens, 2007; Willems \& Van Dooren, 2011; Mansouri \& Rowney, 2014). Initial investigations on accountability completed by Lerner and Tetlock (1999) limited the understanding of accountability to an individual being accountable to another person (Roch \& McNall, 2007). Further research has expanded this definition to include the consideration of individuals being held to account by systems, managers, peers or oneself (Messner, 2009; Hall \& Ferris, 2011; Mero et al., 2012; Turusbekova, Broekhuis, Emans \& Molleman, 2007; Patterson, 2013).

The Theory and Complexity of Accountability Accountability is considered a "notoriously elusive, mobile and ever-expanding concept" (McKernan, 2012, p. 260) with Willems \& Van Dooren (2011) describing accountability as being extremely complex nowadays. Whilst accountability is considered as a significant foundational element in organisations (Hall \& Ferris, 2011) most of the research has explored the hierarchical approach to accountability (Roch \& McNall, 2007; Messner, 2009; Hall \& Ferris, 2011; Mero et al., 2012; Turusbekova et al., 2007) and little research has been done on the perceived relative effectivity of the factors driving accountability. The majority of research that has been conducted occurred in laboratory settings and not in actual workplace situations (Hall \& Ferris, 2011; Hall et al., 2015).

Accountability theory stems from the notion of the contractual relationship between the principal and the agent and the alignment of the assumptions of both parties (Eisenhardt, 1989). This is known as agency theory which forms the basis from which accountability theory has been developed (Mero et al., 2012; Mansouri \& Rowney, 2014). Accountability has multiple aspects to it and it cannot be limited to the basic principles of the principal-agent model (Mansouri \& Rowney, 2014; Eisenhardt, 1989). It expands beyond the simple idea that monitoring will bring about alignment and performance (Mero et al., 2012) taking into account the perceptions of different parties in the relationships more specifically the "individual, subjective and internal nature of accountability" (Hall \& Ferris, 2011, p. 132).

Bovens (2007, p. 449) describes accountability as a "conceptual umbrella" that includes concepts of "transparency, equity, democracy, efficiency, responsiveness, responsibility and 
integrity". Frink \& Klimoski (2004, p. 3) who introduce the social context define accountability as "an actor or an agent in a social context who potentially is subject to observation by some audience(s), including one's self". Frink \& Ferris (1998, p.1261) go as far to stipulate that accountability of conduct is a "universal social norm" emphasizing that "people are agents of their own behaviour, and can be held answerable for their behaviours". Negative and positive associations in relation to accountability have significant impact on individuals (Wikhamn \& Hall, 2014; Thoms, Dose \& Scott, 2002; Hall et al., 2006). Mero et al. (2012) emphasise that the individual being held to account places value on the opinions and judgements of the audience and state that this relationship must exist if a link between individuals, behaviours and effects is to be established. Busuioc \& Lodge (2016) support this, stressing the significance of the varying dynamics of the actual interdependent relationships that exist within an accountability system, and how this ultimately determines behavioural outcomes based on the investment of account-holders or -givers in their respective reputations.

There is an indication that accountability only occurs when it is requested and when the request comes from a position of power (Lindberg, 2013). McKernan (2012, p. 261) calls to question the value of the accountability relationship when forcing accountability from a position of power leading to conformity which may potentially neglect an individual's freedom. However, it cannot be ignored that those individuals who hold power through the action of rewarding or punishing, can have a positive effect on employee performance (Steinbauer, Renn, Taylor \& Njoroge, 2014).

Laird, Harvey \& Lancaster (2015, p. 89) place emphasis on the concept of "felt accountability" and the impact that it has on the desired outcomes. Felt accountability can be considered the individual's subjective interpretation of the enforced mechanisms of accountability within an organisation which may differ based on the perceived reality of the individual (Laird et al., 2015; Wikhamn \& Hall, 2014). Hall, Royle, Brymer, Perrewé, Ferris \& Hochwarter (2006, p. 88) define felt accountability as "an implicit or explicit expectation that one's decisions or actions will be subject to evaluation by some salient audience(s) including oneself, with the belief in the potential for either rewards or sanctions based on these evaluations".

\section{Informal and Formal Accountability}

Accountability within an organisation takes the form of two main approaches; namely via formal and informal sources. 


\section{Informal Accountability}

Informal accountability pertains to the various mechanisms that are enacted within the work place but do not necessarily form part of the formal and defined processes and procedures. Informal accountability includes the norms and values of the organisation, the corporate culture of an organisation and the interpersonal relationships within an organisation (Frink \& Klimoski, 2004; Romzek, LeRoux \& Blackmar, 2012). Busuioc \& Lodge (2016, p. XX) draw attention to the concept of "reputational concern" and how this consideration and investment in relationships, catapults the understanding of accountability to far beyond the limitations of formal processes. Whilst there is acknowledgement that informal accountability systems exist, little is understood about the impact and influence such systems have (Romzek et al., 2012; Frink \& Klimoski, 2004; Sinclair, 1995). Romzek et al. (2012) raise the complicated nature of informal accountability highlighting the fact that it is far less transparent placing emphasis on the implicit nature of the expectations. There are three major forms of informal accountability:

Accountability to Self Self-accountability is often referred to as inward or personal accountability (Sinclair, 1995) and allows for an individual to position themselves as both an audience and agent within the accountability system (Frink \& Ferris, 1998). Hall \& Ferris (2011) argue that scholars have historically taken the construct of individual level accountability for granted. Roberts (1991, p. 357) finds "...accountability introduces a clarifying focus into the lived reality of everyday life - an external view which simultaneously reflects, addresses and confirms self". More recently, emphasis has been placed on individual values and decision making and how these develop accountability (Mansouri \& Rowney, 2014). Responsibility forms the basis of accountability when considering holding oneself accountable for behaviour and performance (McKernan, 2012; Bandura, 1977). McKernan (2012, p. 262) refers to these two constructs as being "deeply entangled". Responsibility to ones-self is based on individual motivating factors and value systems that influence one's actions (Mansouri \& Rowney, 2014; Mulgan, 2000; Sinclair, 1995; Roch \& McNall, 2007). Investigations into self-accountability have been limited (Hall \& Ferris, 2011).

Organisational Culture and Leadership Steinbauer et al. (2014) identifies how a leader's influence occurs through social learning processes, communication and social exchange and is supported by various mechanisms in order to hold individuals accountable for their performance. Ferrell \& Ferrell (2011) highlight the importance of top management creating an ethical and accountable culture. This is supported by Steinbauer et al. (2014) who determined a positive association between ethical leadership and perceived accountability of followers. The evaluation of whether or not an individual should be blamed or praised for 
their performance and behaviour is ultimately determined by top management (Ferrell \& Ferrell, 2011; Wikhamn \& Hall, 2014). Frink \& Klimoski (2004), highlight the need for mutual expectations on a wide range of aspects of organisational life to be established. Gelfand, Lim \& Raver (2004) define accountability within socio-cultural contexts stating that accountability is "the perception of being answerable for actions or decisions, in accordance with interpersonal, social, and structural contingencies, all of which are embedded in particular sociocultural contexts" (p. 137) and further stress the importance of culture in accountability systems. Gelfand et al., (2004) make specific reference to the influence of different social collectives and demonstrate impact through the development of what is described as an "accountability web" (p. 137). Again, this illustrates the complexity of the phenomenon by further suggesting that accountability relationships exit between different identified parties at varying levels within the organisation to varying degrees of strength and direction which are developed through the culture of the organisation and influenced by the external cultural context. They call for further research on culture and accountability on both organisational and societal levels illustrating the significant impact both context and country culture could possibly have on accountability in organisations. There is a dearth of empirical evidence on the role of both culture and leadership in driving accountability.

Accountability to Peers Sinclair (1995) introduces horizontal accountability, describing it as accountability that occurs on a peer-to-peer level. This develops through the process of "reciprocal relationships and a sense of partner accountability" (Romzek, LeRoux \& Blackmar, 2009, p. 5). Willems \& Van Dooren (2011, p. 510) draw attention to the "promising nature of new 'horizontal' forms of accountability" which appears to focus on softer, unseen influences. Companies are adopting more complex forms of design, particularly matrix organisations, which often depend on some form of peer accountability (Sinclair, 1995). This can be reflexive, forcing individuals to automatically act in an accountable way on a continuous basis (Ahrens, 1996). Interestingly, Busuioc \& Lodge (2016, p. XX), suggest that accountability is about individuals "advancing their own reputation" for personal gain when giving account to various account-holders on possible multiple levels. Frink \& Klimoski (2004) indicate that despite the presence of informal accountability systems, individuals do not necessarily accept them. There is a call to better understand how and why individuals potentially feel accountable to their peers (Frink \& Klimoski, 2004; Sinclair, 1995; Roch \& McNall, 2007).

\section{Formal Accountability}

Much of the academic literature is focused on investigations of formal accountability systems within organisations (Hall \& Ferris, 2011). Formal accountability constitutes processes and 
procedures that include mechanisms such as formal reporting relationships, performance evaluations, employment contracts, performance monitoring, reward systems (including compensation), disciplinary procedures, supervisory leadership training, personnel manuals, etc. (Frink \& Klimoski, 2004). These systems usually take on a hierarchical approach (Rus, van Knippenberg \& Wisse, 2012; Sinclair, 1995). Willems \& Van Dooren (2011) express concerns on the effect of formal accountability systems and their reliance on formal processes and sanctions when used in isolation, as they are inflexible and formalistic. There is significant evidence that highlights the positive effects such systems have on performance and that they lead to perceived accountability which has great impact on behaviour (Steinbauer et al., 2014) however, such provisions provide a limited understanding of the actual relationships that occur between actors within the organisation (Busuioc \& Lodge, 2016). Laird et al. (2015) stress the ability of formal accountability systems to remove any ambiguity by clearly identifying the relationship between performance and the rewards or sanctions that may follow.

There are two major forms of formal accountability:

Manager Accountability When exploring formal accountability the concepts of manager accountability and system accountability may be difficult to separate as managers may be enforcing or using the mechanisms of accountability pertaining to the system (Joannides, 2012; Messner, 2009; McKernan, 2012; Roberts, 1991). Joannides (2012) stresses that the ideal form of accountability involves the individual facing a higher authority in person to give an account of their performance. Hierarchical accountability systems ensure that managers hold a degree of power when calling individuals to account (Rus et al., 2012). However, Mansouri \& Rowney's (2014) identified that the mechanisms for control are not necessarily mechanisms for accountability. Mero et al. (2012), adds the concept of valuing the superior to whom the person is giving account to. They conclude that managerial behaviour supports employees' needs to make sense of expectations and that workplace monitoring and control does influence employees being held to account. They further argue that managers are the "most proximal audience" to their employees and thus the most influential when considering accountability.

Wikhamn \& Hall (2014), in their study on accountability and satisfaction find organisational support as a moderator, saying felt accountability depends on what a manager chooses to recognise and whether or not accountability is perceived to be used positively or negatively. Where only failures are recognised when holding an individual to account, and managers are perceived to have excessive control over individuals (Wikhamn \& Hall, 2014). In such cases, accountability is seen as a "stressor" and may have a negative influence (Wikhamn \& Hall, 
2014; Hochwarter, Perrewé, Hall \& Ferris, 2005). Conversely, the ability of managers to make accountability have a positive association, recognising good performance and showing an element of care towards an employee, is understood to have profound effect on overall accountability (Wikhamn \& Hall, 2014; Thoms et al., 2002).

Systems Accountability Extensive research has been conducted into the accountability systems within organisations (Merchant \& Otley, 2006). They stress the importance of the implementation of control and monitoring systems to ensure the organisation remains competitive. Hall \& Ferris (2011, p. 132) highlight the fact that most organisations have some form of accountability mechanisms such as "performance appraisal systems, accounting systems, surveillance mechanisms and computer monitoring". This formal means of accountability include the explicit implementation of procedures, processes and policies that enable the organisation to monitor and control the actions and performance of individuals in the workplace (Hall \& Ferris, 2011). These mechanisms could include aspects of rewards, sanctions or punishment (Frink \& Klimoski, 2004). Patil, Tetlock \& Mellers (2016, p. XX) suggest that "accountability systems have a large impact on how people think" based on where attention is given and how information is processed. However, Laird et al. (2015) highlight that despite accountability systems often being linked to rewards, employees, who have similar roles, responsibilities, demands and expectations, don't necessarily deliver the same level of accountability. Where focus is placed on how well the process is executed rather than the success of the actual outcomes (Patil et al., 2016). Whilst there is little doubt that systems have significant impact, consideration must be given to the effect of these systems and their effect relative to other methods of accountability (Merchant \& Otley, 2006).

\section{Conclusion}

The literature has shown that accountability is not a single occurrence but should rather be viewed as complex, interdependent and integrated, with causal relationships between many factors which include self and others, which interact within broader systems (Lerner \& Tetlock, 1999; Mero et al., 2012; Tenbensal et al., 2014; McKernan, 2012; Hall \& Ferris, 2011; Busuioc \& Lodge, 2016). Willems \& Van Dooren (2011) suggest that the traditional tools and hierarchical approaches are no longer suitable for current organisations. They say due to the formal and rigid nature of systems, the actual practice of accountability is limited, lacking integration and often occurs in a retrospective manner. They place emphasis on the rising benefits of informal systems and stress that a more holistic approach should be adopted. Messner (2009) expresses concern over the current management practices with regards to the restrictive nature of formal mechanisms and calls for more encompassing forms of accountability. This research is an attempt to understand the complex, 
interdependent and integrated factors that occur between individuals and which interact within a broader system to ensure accountability (Tenbensal et al., 2014; McKernan, 2012; Hall \& Ferris, 2011; Ferrell \& Ferrell, 2011 and Steinbauer et al., 2014). In particular, it sets out to understand the different antecedent factors of accountability, the relationship between them and the mechanisms that can be implemented in order to enact them.

\section{RESEARCH QUESTIONS}

Research Question 1: What is understood by the term accountability?

Research Question 2: Which of the factors identified as driving accountability are perceived to be the most impactful?

Research Question 3: Through which mechanisms are each of the accountability factors enacted?

Research Question 4: Can the factors work separately or is there an optimal way to combine them?

\section{RESEARCH METHODOLOGY}

Saunders \& Lewis (2012), highlight the need for exploratory research in an unexplained area in order to provide tentative answers to initial questions. The purpose of this study was to discover new insights into complex systems of accountability, an area of study where little research has been conducted. This investigation followed an inductive approach as prior assumptions were limited and a series of observations allowed for the emergence of potential patterns that led to the formulation of a general theory (Patton, 2002).

\section{Population and Sample}

The population was defined as CEO's, directors, executives, human resource experts and consultants who have knowledge and expertise around trying to hold large groups of employees accountable in organisations. The sampling technique was a two layered nonprobability technique including both judgmental and snowball sampling (Saunders \& Lewis, 2012; Patton, 2002). As the study was qualitative a sample of 20 highly experienced business leaders and experts was considered sufficient. The industries the sample were chosen from covered consulting, education, retail, IT, mining, construction, oil \& gas and finance in South Africa. The first language of all the selected business leaders and experts was English and all the organisations within which they work, operate under the Western business model where the language of business is English. It is important to recognise that whilst we do not consider any cultural influence in this study, In the Global Competitiveness Index (World Economic Forum, 2015-2016) in comparison to 140 countries South Africa, ranked 26th on 'Willingness to delegate authority', 24th on 'Reliance on professional 
management',127th on 'Pay and productivity' and 140 out of 140 on 'Cooperation in labouremployer relations This may be of significance when considering the context in which the study took place. Furthermore, as per The World Bank (2011) in a report on Accountability in Public Services in South Africa, there appears to be evidence of a significant lack of accountability by national and local government in South Africa often leading to service delivery protests. However, minimal consideration has been given to accountability in South African business.

\section{Data Collection}

Twenty face-to-face, semi-structured, in-depth interviews were conducted lasting on average for 45 minutes. The semi-structured interview questions were developed from the research questions. The structure of the interview guideline was to ensure that open dialogue was developed (Zikmund, Babin, Carr \& Griffin, 2013). The interview started with a brief description of the context of the study. Following this, eight open-ended, non-leading questions were asked and the participants were expected to respond based on their personal perceptions drawing, on previous experiences. Participants were encouraged to answer the questions openly and freely in order to support the exploratory nature of the research. At one point participants were asked to rate the relative importance of the factors they had identified using a fixed point scale (Saunders \& Lewis, 2012). The interview continued until a point of data saturation was reached where no new insights were provided by the interviewee. Each interview was recorded with permission from the interviewee. A pilot investigation of two preinterviews were conducted in order to test the interview guideline and the technique of the interviewer. This led to a few adjustments (Saunders \& Lewis, 2012).

\section{Data Analysis}

The analysis of the data was concerned with the identification of themes and insights (Zikmund et al., 2013). Each interview took approximately 3 hours to analyse in full following all six stages of the phases of thematic analysis as described by Braun \& Clarke (2006). Codes were generated in a systematic way and assigned to the features of the data. The identified codes were consolidated to represent potential themes. The themes were reviewed and checked against each other and thematic maps were established in relation to the research questions (Braun \& Clarke, 2006). Each construct was then named and the number of times it was mentioned, was counted and rank ordered.

\section{Research Limitations}

Qualitative research can be considered subjective by nature and can be affected by a number of different biases (Saunders \& Lewis, 2012; Zikmund et al., 2013). Interviewer bias and response bias might have taken effect when conducting the interviews and analysing the 
data. The sample selected consisted of executives, senior managers and experts, there was no attempt to establish the opinions of individuals in lower level positions in the organisations. Only individuals from one metropolitan region in South Africa were represented in the sample therefore a geographical bias could exist.

\section{RESULTS}

\section{RESEARCH QUESTION 1: What is understood by the term accountability?}

The first interview question dealt with each interviewee's understanding of the concept of accountability. As the concept had been identified as a complex phenomenon (Bovens, 2007; Willems \& Dooren, 2011; Mansouri \& Rowney, 2014) it was important to establish a common definition. All interviewees were able to articulate clearly their concept of accountability. Some views were narrow and focused whilst others adopted a more broad perspective. Table 1 illustrates the five most frequently mentioned aspects of the concept of accountability.

Table 1: Understanding of the Concept of Accountability

\begin{tabular}{|c|l|c|}
\hline Rank & \multicolumn{1}{|c|}{ Construct } & Frequency \\
\hline 1 & $\begin{array}{l}\text { The completion of a given task, within a time frame, to a set } \\
\text { standard, with failure to deliver resulting in a consequence }\end{array}$ & 15 \\
\hline 2 & $\begin{array}{l}\text { Achieving or completing the jobs or tasks that have been } \\
\text { assigned to an individual (or role) }\end{array}$ & 8 \\
\hline 3 & $\begin{array}{l}\text { Taking final responsibility for all or some aspects of a given } \\
\text { task, explaining or justifying the outcome }\end{array}$ & 4 \\
\hline 4 & $\begin{array}{l}\text { An individual honouring, executing and delivering on what } \\
\text { he/she has been contracted to do }\end{array}$ & 4 \\
\hline 4 & Behaving, living and delivering in line with company values \\
\hline
\end{tabular}

In analysing these constructs, the majority of participants agreed that accountability was in relation to a task or job, the completion of that task or job, the delivery and outcome of the task or job, that there is a consequence element to it and that it occurs within a given time frame. This is used as the definition for the rest of this article. Many interviewees mentioned the complex nature of accountability, with a participant stating "Accountability is a tricky one and rather nebulous, accountability does not live alone, it lives in the universe of business and it operates in unison with many other elements". A top CEO opened the discussion by saying "I don't believe in accountability" and explained that it is "just one element of the employment scenario" rather than an entity on its own. The complexity of accountability 
adding to the challenge of understanding the concept is discussed by Willems \& Dooren (2011) and McKernan (2012).

Interestingly, the interviewees did not make mention of any implicit expectations, they all referred to explicit commitments and requirements. Participants failed to highlight the concept of an identified account-holder or mention the manager. This confirms the notion that the 'to whom' aspect is largely misunderstood and that little consideration is given to the relationship between an account-holder and an account giver (Bovens, 2007; Messner, 2009; McKernan, 2012; Joannides, 2012; Hall et al., 2015; Busuioc \& Lodge, 2016). Some participants were unable to separate the concepts of accountability and responsibility and referred to them interchangeably which is supported by McKernan's (2012) description of the two concepts being deeply entangled.

\section{RESEARCH QUESTION 2: Which of the factors identified as driving accountability are} perceived to be the most impactful?

The second interview question requested participants to list what they perceived to be drivers (antecedents) of accountability within organisations. Participants offered a wide range of factors. In the third interview question participants were then required to allocate a numerical weighting to their identified factors. Each participant was given 100 points to distribute across their factors and were expected to place a higher number of points on the factors they believed to be more important in driving accountability. Many of the participants found this particular question challenging and it led to a significant amount of discussion. One participant was unable to allocate points stating that it is "too difficult because they are all interlinked". These points were summed across the sample to give a total point score to indicate the relative importance of the factors as ranked in Table 2.

\section{Table 2: The Identified Antecedents and Their Relative Weightings}

\begin{tabular}{|c|l|c|}
\hline Rank & \multicolumn{1}{|c|}{ Construct } & Total Points \\
\hline 1 & Culture of an organisation & 412 \\
\hline 2 & $\begin{array}{l}\text { Systems in place within an organisation (including } \\
\text { performance management systems, measurement system, } \\
\text { rewards and sanctions, policies and legal frameworks) }\end{array}$ & 405 \\
\hline 3 & Strategic leadership of the organisation & 281 \\
\hline 4 & The individual & 171 \\
\hline 5 & Clarity of role and tasks & 155 \\
\hline 6 & Peers & 95 \\
\hline 7 & Organisational values, ethics, trust and transparency & 93 \\
\hline 8 & Structure of the organisation & 85 \\
\hline 9 & Recruitment and selection & 40 \\
\hline 9 & Learning, training and development & 40 \\
\hline
\end{tabular}




\begin{tabular}{|c|l|c|}
9 & Alignment within the organisation & 40 \\
\hline 12 & Clients, customers, context and macro-environment & 28 \\
\hline 13 & Feedback mechanisms & 25 \\
\hline 14 & Managers & 20 \\
\hline 15 & Nature of disclosure & 10 \\
\hline 16 & Output of an organisation or team & 0 \\
\hline & Total & 1900 \\
\hline
\end{tabular}

Systems in place in an organisation, the culture of an organisation, the clarity of role and tasks, the strategic leadership of the organisation and the individual were identified as the top five antecedents that drive accountability. These were termed primary factors and will be discussed in turn.

Systems All but one of the interviewees mentioned systems as a factor. A director stressed that "it's about the standards that you set...the performance expectations, by setting high standards, people will rise to them. It's about being consistent and communicating that". A senior manager reasoned that "behaviour is driven through what the system dictates". Hall \& Ferris (2011) indicate that most organisations have some form of accountability mechanisms in place which are formal and explicitly implemented. Merchant \& Otley (2006) stress the significance of the impact and influence these systems have in driving accountability.

However, some participants made reference to the hindering nature of systems with one individual commenting that "people don't actually like performance management processes because they feel policed, undermined and caught out". This supports the concept of the dark side of accountability as raised by Laird et al. (2015) that accountability imposed by the systems can act as a stressor and potentially have a negative effect. One participant stated the importance of felt ownership of the systems, indicating that systems can drive specific behaviours through felt accountability. Another executive stressed where an organisation has strong consequences to systems employees tend to cover up mistakes.

Culture One top executive said, "it is all about the culture! I am not a big fan of over reliance on accountability systems". One director reflected "one of the toughest things is to build a safe culture where people are open and honest and are able to talk about their failings". One executive allocated $70 \%$ of his points to culture saying that he didn't wish to "diminish the role of leadership but purely because without the right culture, centred around trust and fairness, there won't be any accountability". An executive stressed that "where you have an ownership culture, a culture of trust, you have a direct correlation to high levels of accountability". Many participants debated whether culture or systems where more effective 
in holding individuals to account. It was determined that whilst systems are effective and necessary, the culture of an organisation will always override the formal system and that you will not have accountability within the organisation if the culture does not promote it.

The importance of culture to drive accountability supports Willems \& Van Dooren's (2011) suggestion of the benefits of the informal systems and Messner's (2009) concerns over the restrictive nature of systems and the need for a more holistic and encompassing approach to accountability. Some mention of culture is made by Ferrell \& Ferrell (2011) who highlight the importance of creating an accountability culture and Steinbauer et al. (2014), who make reference to the support systems provide in creating such a culture. Informal accountability in the form of culture has been under-researched in accountability studies to date and this points to the importance of this finding.

Strategic leadership of the organisation Whilst not explicitly discussed in the literature, many participants raised the role of executive leadership as a driver of culture with one individual stressing the importance of "leadership subscribing to the highest levels of accountability, with transparency around the accountability". One top executive explained that "the way that leadership acts to create these norms, values, behavioural incentives which are embedded in the culture, the way the leadership acts continually from the head down, cascades on through the organisation and creates a culture of accountability". A few participants stressed that the CEO actually sets the culture which is often driven through the observed behaviours of leadership. This supports the work of Ferrell \& Ferrell (2011) and Steinbauer et al. (2014) who highlight the significant influence leadership has on creating an ethical and accountable culture in their followers. However, much like culture, there is minimal literature that identifies the significance of strategic leadership being a considerable influencing factor on felt accountability.

Clarity of role and tasks The findings show that you cannot hold someone accountable if they do not know what is expected of them or do not have the ability to meet expectations. Two executives went as far as to claim that there is no possibility of accountability without role or job clarity. One saying "Clarity is significant. I am very much a believer in a mutually exclusive set of responsibilities". Whilst Frink \& Klimoski (2004) identify clarity of role by highlighting the importance of mechanisms such as the employment contract, it is understood in the literature as forming part of systems that drive accountability rather than being identified as an individual factor. The interviewees saw it as a separate process. 
The individual The role of the individual employee in driving accountability was found to be key. One senior manager stated "we hire individuals that are individually accountable - that it is one of their intrinsic values that they would need to have in order to come on board". Other participants referred to accountability being subjective as individuals have to volunteer to it themselves. One participant stated that "Ultimately, the most effective forms of creating behavioural norms that people can subscribe to, would be intrinsic. In other words, they would choose to hold themselves accountable". Mansouri \& Rowney (2014), McKernan (2012) and Joannides (2012) support this finding emphasising a sense of responsibility and individual values in accountability with a need to focus on aligning individual values with organisational values during recruitment. Messner (2009) shows without individuals having the intrinsic ability to hold themselves accountable, regardless of the context and supporting mechanisms, enforcing accountability will be challenging.

Managers A surprising finding was that the manager was only ranked $14^{\text {th }}$ in Table 2 whilst having featured strongly in the literature review. This does not support the significant emphasis by many authors including Mero et al. (2012) who identify managers as the most influential when considering a system of accountability. One executive said that "high levels of managerial control reduces accountability, low levels of managerial control equals high levels of accountability". However in defence of the importance of managers a director said that "managers implement the system and this either enhances culture or not".

There is limited literature that explicitly reviews the relative importance of different factors that influence accountability. Hall et al. (2015) stress the need for research to be conducted into the extent to which employees prioritize accountabilities to different sources. Hence the findings from this study are significant. Of the five primary factors three fall into the category of informal accountability and two into the category of formal accountability. This supports Ferrell \& Ferrell (2011) and Steinbauer et al. (2014) emphasis on the importance of the establishment of organisational shared norms and expectations and Willems \& Van Dooren (2011) and Messner (2009) who emphasise the benefits of the informal systems of accountability whilst stressing a holistic approach to enforcing consequences.

\section{RESEARCH QUESTION 3: Through which mechanisms are each of the accountability factors enacted?}

The fourth interview question asked the interviewees to consider which mechanisms could be used to ensure that the identified factors were enacted and experienced. Frink \& Klimoski 
(2004) state that the reason for implementing accountability mechanisms is to control the actions and decisions of employees and to ensure expectations are met. Hall et al. (2006) who define felt accountability in the context of implicit and explicit expectations placed on individuals also emphasise the need for mechanisms to be implemented. Table 3 presents the number of interviewees who mentioned the primary factor as having mechanisms that should be used to enact accountability and the number of mechanisms they mentioned. Not all participants were able to describe a mechanism that supported the factor they had named.

Table 3: Number of Mechanisms Mentioned per Primary Factor

\begin{tabular}{|c|l|c|c|}
\hline Rank & \multicolumn{1}{|c|}{ Primary Construct } & $\begin{array}{c}\text { Number of } \\
\text { interviewees able } \\
\text { to name } \\
\text { mechanisms }\end{array}$ & $\begin{array}{c}\text { No. of } \\
\text { mechanisms } \\
\text { mentioned }\end{array}$ \\
\hline 1 & Systems in place within an organisation & 19 & 13 \\
\hline 2 & Culture of an organisation & 9 & 9 \\
\hline 3 & The individual & 8 & 6 \\
\hline 4 & Clarity of role and tasks & 6 & 3 \\
\hline 5 & Strategic leadership of the organisation & 5 & 11 \\
\hline
\end{tabular}

The three most frequently suggested mechanisms for each of the factors will be discussed.

Table 4: Systems Mechanisms to Drive Accountability

\begin{tabular}{|c|l|c|}
\hline Rank & \multicolumn{1}{|c|}{ Construct } & Frequency \\
\hline 1 & $\begin{array}{l}\text { Formal processes for linking good performance to rewards, recognition } \\
\text { (formal/informal), remuneration, incentives and promotion or progress } \\
\text { through the organisation }\end{array}$ & 18 \\
\hline 2 & $\begin{array}{l}\text { Performance review systems based on performance contracts leading } \\
\text { to personal development plans }\end{array}$ & 17 \\
\hline 3 & Ongoing feedback and recurring conversations & 15 \\
\hline
\end{tabular}

A significant emphasis was placed on formal processes that link good performance to rewards, recognition, incentives and promotion. One executive reflected, "It always surprises me how people respond to what hits their back pocket. Why don't you just strive to do the right thing, are financial incentives seen as coercing people to do the right thing...maybe it is but people respond to it" and another highlighting the strong link between measurement and reward, stipulating that "we get what we measure and what is rewarded". Most participants said that performance management systems are "critical and must be in place" however, there appeared to be conditions that determined the effectiveness of the systems. A number 
of participants stressed the importance of the implementation of the systems with one business owner stating that "you can have the best system [in place] but if it is poorly implemented, it becomes problematic" and another general manager stating that "the downfall of these systems is human implementation". Communication, feedback and conversations were seen as vital to support accountability. A director stated that "we need development of all leaders on how to effectively have these tough discussions", and added "one of the things that I am a huge believer in is real-time feedback - that's consequence management". In reflecting on the difficulty of learning how to use performance management systems and consequences one executive stated "to understand these things, consequences, accountability, position, what goes with the positions, failures, dealing with results not delivered, dealing with multiple stakeholders, I think that takes time, takes experience and if you lucky a good boss or two and hard graft".

These findings support Hall \& Ferris (2011) who indicate that most organisations have some form of these systems in place and Merchant \& Otley (2006) who refer to the importance of the extrinsic outcomes of the mechanisms of systems as being a key aspect of accountability.

\section{Table 5: Culture Mechanisms to Drive Accountability}

\begin{tabular}{|c|l|c|}
\hline Rank & \multicolumn{1}{|c|}{ Construct } & Frequency \\
\hline 1 & $\begin{array}{l}\text { Development of social capital and } \\
\text { behavioural relationships within the } \\
\text { organisation }\end{array}$ & 6 \\
\hline 2 & $\begin{array}{l}\text { Vision, mission and organisational } \\
\text { values }\end{array}$ & 4 \\
\hline 3 & $\begin{array}{l}\text { Cultural survey/ employee climate } \\
\text { survey }\end{array}$ & 3 \\
\hline
\end{tabular}

Most of the participants stressed the importance of behaviour and relationships when considering culture. Frink \& Klimoski (2004) and Sinclair (1995) identify shared norms and expectations and organisational beliefs and attitudes as key to driving accountability. A participant stressed the importance of values, sharing that "if your accountability system drives results at any cost, you are going to get a certain type of culture but if it is looking at sustainable and enhanced performance, it is basically saying that not everything we are doing is going to work but as long as most of it works. If we do ugly things in the process of getting to great results, that is not okay, that's giving you a different kind of culture". One general manager wrestled with the concept of social capital as a tool for enabling culture saying "it's the social deposits you make every day that ultimately help build up relationships which helps drive accountability". Social capital deals specifically with the behaviour of 
employees on an individual level and aims to extract value from the social network developed in an organisation, creating impact and influence through collective agreement. This, in many ways, refers directly to Busuioc \& Lodge's (2016) summation that the overall outcomes of accountability depend largely on the amount of an individual's reputational investment when considering such relationships.

This is a new finding as the development of social capital is not well researched in the context of accountability. The few participants that identified employee climate surveys and cultural audits indicated that they can be used to "give you an indication of the culture of accountability" however, concerns were expressed that such surveys are "retrospective in nature". Although Ferrell \& Ferrell (2011), Steinbauer et al. (2014) and Sinclair (1995) mention the importance of leadership and culture when considering accountability, minimal reference is made to specific mechanisms that can support the implementation of a culture of accountability. The findings support the notion that culture can have an inhibiting effect if it is not focused or aligned to driving accountability.

\section{Table 6: Individual Mechanisms to Drive Accountability}

\begin{tabular}{|c|l|c|}
\hline Rank & \multicolumn{1}{|c|}{ Construct } & Frequency \\
\hline 1 & $\begin{array}{l}\text { Individual values, personal upbringing } \\
\text { and individual attitude }\end{array}$ & 7 \\
\hline 2 & Recruitment and selection & 6 \\
\hline 2 & $\begin{array}{l}\text { Training, development and use of } \\
\text { personal development plans }\end{array}$ & 6 \\
\hline
\end{tabular}

Particular emphasis was placed on the qualities and values of an individual and how they are directly related to having the ability to hold one's self accountable. This was often linked to recruitment and selection as a mechanism. One director shared "we are tailoring our recruitment processes to make sure that the very people we are bringing in are people who will feel comfortable with the accountability". By selecting people who hold themselves accountable and training them to be able to meet the job requirements the accountability within an organisation is enhanced. A director agreed that mechanisms can be transferred to act as an enabler for a different factor stressing that what is "critically important from an organisational perspective is developing the culture in the business through mentoring". Personal development plans (PDP's) were identified as a mechanism for both individuals and systems. A director stressed the importance of the individual in the development of the personal development plan highlighting that "people want to be taken seriously, they want to 
be heard". Another top CEO found that PDP's allow areas of poor performance identified in the performance review to be remedied to enhance accountability.

One senior executive reflected deeply on the concept that systems cannot change the individual and considered that the system mechanisms are only effective if the individual is the right fit for the organisation. On the contrary, one participant discounted any individual mechanisms highlighting that "we take systemic management of people and process very seriously and we don't leave it up to the individual". This supports Mansouri \& Rowney (2014) and McKernan (2012) who express the significance of individual values, ethics and motivating factors as a driving force for accountability. Little information is provided in the literature that addresses selection directly in driving accountability. Messner (2009) and Sinclair (1995) stresses the importance of employees maintaining shared values and beliefs and the need to develop collective norms but no mention is made of specifically selecting individuals for their intrinsic ability to hold one's self accountable.

Table 7: Clarity of Role and Task Mechanisms to Drive Accountability

\begin{tabular}{|c|l|c|}
\hline Rank & \multicolumn{1}{|c|}{ Construct } & Frequency \\
\hline 1 & Job and task descriptors & 5 \\
\hline 2 & Clear and effective communication & 4 \\
\hline 3 & $\begin{array}{l}\text { RACl (responsibilities, accountability, } \\
\text { consult and inform) }\end{array}$ & 2 \\
\hline
\end{tabular}

Although mentioned separately these three mechanisms are interrelated. The job and task descriptors need to be clearly communicated and cover the four $\mathrm{RACl}$ components. One general manager placed particular emphasis on job descriptions stressing that "you can't really hold someone accountable if they don't know". Another reviewed the integration of the organisations objectives, KPI's and job descriptions. One CEO considered the issues faced when designing the scope of a job description. He stated that "there is always an excuse, if you make it too specific and the project fails, the response is, I did everything you told me to. If you make it too broad and the project fails, the response still is, I did everything you told me to". A number of the interviewees stressed that employees need to be "both willing and able...regardless of how well the job description is formulated, if the individual does not have the skills to do the job, then it makes it difficult to hold them accountable".

Laird et al. (2015) and Wikhamn \& Hall (2014) place emphasis on the concept of felt accountability and the need for clarification of role expectations and behaviour criteria. Wikhamn \& Hall (2014) highlight the risk of inconsistencies and subjectivity occurring due to 
individual subjectively interpreting the demands placed on them. This supports the key finding that emerged where participants explicitly expressed that you cannot hold an individual accountable if they are unsure or unclear of what is expected of them.

Table 8: Strategic Leadership Mechanisms to Drive Accountability

\begin{tabular}{|c|l|c|}
\hline Rank & \multicolumn{1}{|c|}{ Construct } & Frequency \\
\hline 1 & $\begin{array}{l}\text { Vision, mission and strategic planning } \\
\text { process }\end{array}$ & 3 \\
\hline 1 & Communication and the use of stories & 3 \\
\hline 1 & $\begin{array}{l}\text { Leadership development programmes } \\
\text { and leadership skills }\end{array}$ & 3 \\
\hline
\end{tabular}

Participants placed significant emphasis on the importance of leaders executing on the vision, mission and strategy of the organisation and that leadership was responsible for successful implementation and usage of the previously identified systems. One participant said "it comes back to the system of engagement, so the organisation implements the system, the people live in that eco-system but if the organisation and its leadership does not drive it, it won't go anywhere. If the system is not articulated it will not work". Another participant stressed the importance of story-telling as a mechanism saying it is "strategic and deliberate story telling" that supports and influences followers and the system of accountability. One participant reflected on the importance of developing strategic leaders who can influence accountability throughout the company.

That fact that few participants were able to offer mechanisms that allow for the strategic leadership of an organisation to enact accountability supports the notion that formal systems are often implemented to address accountability issues that stem from informal influences. Willems \& Van Dooren (2011) make reference to the rising benefits of the informal systems of accountability and the need for a more holistic and encompassing approach. However, the literature does not go as far as to discuss implementing mechanisms that allow for the informal systems such as leadership to be enacted or experienced.

RESEARCH QUESTION 4: Can the factors work separately or is there an optimal way to combine them?

The fifth interview question allowed participants to consider whether the factors could work in isolation and still have an impact on ensuring accountability. The results are presented below in Table 9. 
Table 9: The Effectiveness of Factors Working in Isolation or in Combination

\begin{tabular}{|c|l|c|}
\hline Rank & \multicolumn{1}{|c|}{ Construct } & Frequency \\
\hline 1 & $\begin{array}{l}\text { Factors work better in combination as they occur } \\
\text { in an integrated, interlinked, interconnected } \\
\text { system }\end{array}$ & 17 \\
\hline 2 & Factors can work in isolation but only up to a point & 3 \\
\hline
\end{tabular}

All participants felt that the factors work better in combination. One senior manager referred to the integrated nature of the factors stating that they "feed off each other". A director concurred saying "it's about optimizing their alignment". Another stressed that when the factors work in combination they provide "an amplifying effect" however it was also emphasised that "amplification can be flipped either way, if you have a high performing, highly accountable individual, without any of the others factors, the missing factors would amplify each other in a negative way to the point where the individual will just stop working, this is what we call learned helplessness".

These findings support the view of a number of authors who identify various interdependent causal relationships that occur between an individual and a set of separate entities when instilling accountability (Mero et al., 2012; Tenbensal et al., 2014; McKernan, 2012; Hall \& Ferris, 2011; and Steinbauer et al., 2014). Willems \& Dooren's (2011) maintain that no single factor can work in isolation and that a significant number of interactions need to occur for the system of accountability to have an effect. They find accountability to be a process rather than a single event. The interrelated questions: who, to whom, for what and by which means used by Joannides (2012) and Bovens (2007) to frame accountability also supports this finding.

Three participants identified that some factors may be able to work in isolation but only up to a "ceiling" point thereafter additional factors would be needed. This is of significance and introduces the concept of a critical threshold when considering accountability and suggests that a factor could have an effect up to a point after which another factor needs to be introduced to enforce accountability. Laird et al. (2015) states that despite implementation of system mechanisms, individuals don't necessarily deliver to the same level of accountability inferring that additional factors need to be at work in order to ensure the equality of levels of accountability among employees.

In the sixth interview question participants were required to consider a holistic view of the overall interactions among the factors. All 20 participants had a differing view of the ways in 
which their identified factors could be pulled together. The majority of participants felt that the factors should be integrated but that the relationship between them is highly complex however, none of them could integrate them into a cohesive model. One senior manager said, "everything has a knock on effect" with another describing how factors are united by the CEO acting as a nucleus with the other factors connected and attracted to the CEO. Another director stated "If you have hired well, and you have got people with ownership and commitment and 'stick-at-it-ness', you just need to have structure, communication and leadership that enables that and that does not get in the way of individual ownership and commitment". A number of participants made reference to the use of culture producing an overall effect.

\section{SYSTEM OF ACCOUNTABILITY MODEL}

It is clear that there is an interaction between the antecedent factors and that there needs to be a cyclical process to ensure some form of a catalytic effect. A model was developed from the findings to integrate and navigate the complexity of accountability. It illustrates the interdependence of the antecedent factors and shows how they work collectively in a reenforcing way to enable organisations to achieve maximum levels of accountability. The model is shown in Figure 1.

Figure 1: The 'System of Accountability' Model

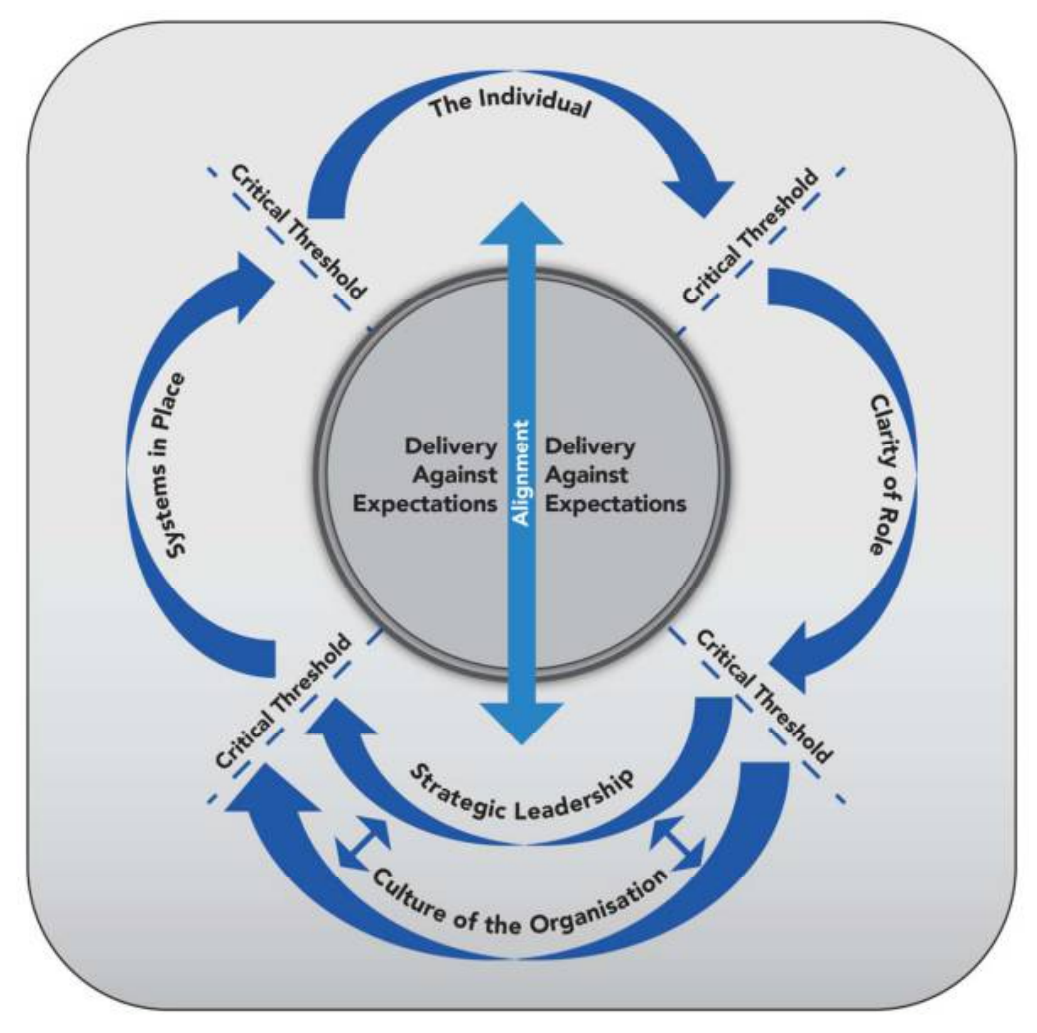


The overall desired outcome of the accountability system is illustrated in the central circle where individuals are expected to deliver against expectations. The model then shows the five key factors that drive accountability within the organisation and support individuals to perform well. They are all significant and necessary to ensure an optimal level of accountability is exercised. Each factor has specific key mechanisms that can be used to ensure the factor is enacted and experienced as detailed in Tables 4 to 8 . The model supports the work of by Tenbensal et al. (2014), Mero et al. (2012), Lerner \& Tetlock (1999), McKernan (2012) and Hall \& Ferris (2011) who all identified that accountability is a result of complex, interdependent and integrated, causal relationships between factors. However, none of these authors produced an integrated model of the factors.

\section{IMPLICATIONS FOR MANAGEMENT}

There are a number of significant implications for management as a result of the findings established through this research and illustrated in the 'System of Accountability' model. All established factors should be considered however, a key new finding that emerged is the concept of a factor having a critical threshold. This refers to the maximum level of accountability that can be experienced due to a single factor. By applying the key mechanisms each factor can only ensure a certain level of accountability, the critical threshold point, after which an additional factor needs to be introduced in order to elevate the level of accountability. In situations where a factor has not reached the desired critical threshold, regardless of the introduction of other factors, the overall effectiveness of the system of accountability will be limited. If the critical threshold is not met the factor can become inhibiting. Leaders and HR Managers should aim to ensure that all five primary factors shown in the model are in effect and experienced by employees through the implementation of the key mechanisms established in the research. Leaders and HR Managers must ensure that the mechanisms that are implemented allow for the factor to reach critical threshold and that factors are introduced in a systematic and calculated way. In cases where a factor is seen to be limiting, mechanisms need to be reviewed and redesigned in order to have the desired effect.

Strategic Leadership and Culture are intertwined as the one establishes the other. This is indicated by the two arrows linking these two parts of the model. The senior leaders need to focus on continually spelling out and role modelling the vision, mission and accountability culture of the organisation. Management development programmes must be in place to 
ensure the requisite leadership skills are available to drive accountability of the staff. When implementing systems to support accountability in the organisation, managers should use positive reinforcement through the range of rewards. These should be facilitated through frequent feedback conversations to continually track progress towards expected outcomes and should fully support the culture of the organisations. It is also essential that the systems which impose consequences for poor performance are used.

Organisations should ensure that the right kind of individual is brought into the organisation: Individuals who have a strong tendency for personal accountability. The arrow down the centre of the model, marked alignment, shows the importance of ensuring that the individual's values are directly aligned with the organisation during both recruitment and development. Managers should ensure that the role or task assigned to an individual is clearly stipulated and understood through well-developed job descriptors and performance agreement discussions. Eliminating ambiguity is essential and ensures that individuals cannot claim they did not know and so cannot be held accountable.

\section{FUTURE RESEARCH}

Research into understanding what managers perceive to be the drivers of accountability versus what their employees perceive would be useful. This could be further extrapolated to include an investigation that seeks to understand the factors that influence accountability at different levels within an organisation, comparing senior level employees with sub-ordinates or lower level employees. A study of how peer-to-peer accountability is experienced in matrix organisations could be conducted. Understanding the relationship between the type of systems implemented to ensure accountability and the culture of the organisation would be useful and finally, understanding the implications of an individual's cultural background and the country context within which they operate, have on their perceived accountability within a team or organisation is an area that is largely unexplored.

\section{CONCLUSION}

The literature shows that accountability is a core concept that is central to performance in organisations. Despite this, a significant amount of ambiguity remains with little evidence of how to effectively implement systems of accountability in order to ensure improved performance of individuals, teams and organisations. This research set out to contribute in closing the gap that exists in the literature. The findings that emerged from the 20 leaders that were interviewed established a clear understanding as to the best practice in the field resulting in the development of the 'System of Accountability' model which integrates the five key primary constructs that emerged as the main factors that drive accountability. 
This study contributes to the literature through empirical research that provides key insights into the different factors which drive accountability and the understanding of the complexity of the interrelatedness of these factors. It is hoped that this research contributes to the practice of organisation leaders, human resource managers and consultants who are seeking to drive accountability and improve performance within organisations.

\section{REFERENCES}

Ahrens, T. (1996). Styles of accountability. Accounting, Organizations and Society, 21(2), 139-173.

Bandura, A. (1977). Self-efficacy: toward a unifying theory of behavioral change. Psychological Review, 84(2), 191.

Bovens, M. (2007). Analysing and assessing accountability: a conceptual framework1. European Law Journal, 13(4), 447-468.

Braun, V., \& Clarke, V. (2006). Using thematic analysis in psychology. Qualitative Research in Psychology, 3(2), 77-101.

Breaux, D. M., Munyon, T. P., Hochwarter, W. A., \& Ferris, G. R. (2009). Politics as a moderator of the accountability-job satisfaction relationship: Evidence across three studies. Journal of Management, 35(2), 307-326.

Brennan, N. M., Kirwan, C. E., \& Redmond, J. (2016). Accountability processes in boardrooms: a conceptual model of manager-non-executive director information asymmetry. Accounting, Auditing \& Accountability Journal, 29(1), 135-164.

Busuioc, M. and Lodge, M. (2016), Reputation and Accountability Relationships: Managing Accountability Expectations through Reputation. Public Administration Review. doi: 10.1111/puar.12612Eisenhardt, K. M. (1989). Agency theory: An assessment and review. Academy of Management Review, 14(1), 57-74.

Ferrell, O. C., \& Ferrell, L. (2011). The responsibility and accountability of CEOs: The last interview with Ken Lay. Journal of Business Ethics, 100(2), 209-219.

Frink, D. D., \& Ferris, G. R. (1998). Accountability, impression management, and goal setting in the performance evaluation process. Human Relations, 51(10), 1259-1283.

Frink, D. D., \& Klimoski, R. J. (2004). Advancing accountability theory and practice: Introduction to the human resource management review special edition. Human Resource Management Review, 14(1), 1-17. doi: 10.1016/j.hrmr.2004.02.001

Gelfand, M. J., Lim, B. C., \& Raver, J. L. (2004). Culture and accountability in organizations: Variations in forms of social control across cultures. Human Resource Management Review, 14(1), 135-160. 
Hall, A. T., \& Ferris, G. R. (2011). Accountability and extra-role behavior. Employee Responsibilities and Rights Journal, 23(2), 131-144. doi: 10.1007/s10672-010-9148-9

Hall, A. T., Frink, D. D., \& Buckley, M. R. (2015). An accountability account: A review and synthesis of the theoretical and empirical research on felt accountability. Journal of Organizational Behavior.

Hall, A. T., Royle, M. T., Brymer, R. A., Perrewé, P. L., Ferris, G. R., \& Hochwarter, W. A. (2006). Relationships between felt accountability as a stressor and strain reactions: The neutralizing role of autonomy across two studies. Journal of Occupational Health Psychology, 11(1), 87.

Hochwarter, W. A., Perrewé, P. L., Hall, A. T., \& Ferris, G. R. (2005). Negative affectivity as a moderator of the form and magnitude of the relationship between felt accountability and job tension. Journal of Organizational Behavior, 26(5), 517-534.

Joannides, V. (2012). Accounterability and the problematics of accountability. Critical Perspectives on Accounting, 23(3), 244-257. doi: 10.1016/j.cpa.2011.12.008

Laird, M. D., Harvey, P., \& Lancaster, J. (2015). Accountability, entitlement, tenure, and satisfaction in Generation Y. Journal of Managerial Psychology, 30(1), 87-100.

Lerner, J. S., \& Tetlock, P. E. (1999). Accounting for the effects of accountability. Psychological Bulletin, 125(2), 255.

Lindberg, S. I. (2013). Mapping accountability: core concept and subtypes. International Review of Administrative Sciences, 79(2), 202-226. doi: 10.1177/0020852313477761

Mansouri, M., \& Rowney, J. I. A. (2014). The Dilemma of Accountability for Professionals: A Challenge for Mainstream Management Theories. Journal of Business Ethics, 123(1), 4556.

McKernan, J. F. (2012). Accountability as aporia, testimony, and gift. Critical Perspectives on Accounting, 23(3), 258-278. doi: 10.1016/j.cpa.2011.12.009

Merchant, K. A., \& Otley, D. T. (2006). A review of the literature on control and accountability. Handbooks of Management Accounting Research, 2, 785-802. doi: 10.1016/S1751-3243(06)02013-X

Mero, N. P., Guidice, R. M., \& Werner, S. (2012). A field study of the antecedents and performance consequences of perceived accountability. Journal of Management, 40(6), 1627-1652. doi: 10.1177/0149206312441208

Messner, M. (2009). The limits of accountability. Accounting, Organizations and Society, 34(8), 918-938. doi: 10.1016/j.aos.2009.07.003

Mulgan, R. (2000). 'Accountability': An ever-expanding concept?. Public Administration, 78(3), 555-573.

Patterson, K. (2013). Crucial accountability. Leadership Excellence, 30(8), 5-6. 
Patton, M. Q. (2002). Qualitative research and evaluation methods. Sage. Thousand Oaks, $C A$.

Patil, S. V., Tetlock, P. E., \& Mellers, B. A. (2016). Accountability Systems and Group Norms: Balancing the Risks of Mindless Conformity and Reckless Deviation. Journal of Behavioral Decision Making. Doi:10.1002/bdm.1933Roberts, J. (1991). The possibilities of accountability. Accounting, Organizations and Society, 16(4), 355-368.

Roch, S. G., \& McNall, L. A. (2007). An investigation of factors influencing accountability and performance ratings. The Journal of Psychology, 141(5), 499-524. doi: 10.3200/JRLP.141.5.499-524

Romzek, B. S. (2015). Living Accountability: Hot Rhetoric, Cool Theory, and Uneven Practice. PS: Political Science \& Politics, 48(01), 27-34.

Romzek, B. S., LeRoux, K., \& Blackmar, J. (2009, October). The Dynamics of informal accountability in networks of service providers. In the 10th Public Management Research Association Conference.

Romzek, B. S., LeRoux, K., \& Blackmar, J. M. (2012). A preliminary theory of informal accountability among network organizational actors. Public Administration Review, 72(3), 442-453.

Rus, D., van Knippenberg, D., \& Wisse, B. (2012). Leader power and self-serving behavior: The moderating role of accountability. The Leadership Quarterly, 23(1), 13-26. doi: 10.1016/j.leaqua.2011.11.002

Saunders, M., \& Lewis, P. (2012). Doing research in business \& management. England: Pearson

Shearer, T. (2002). Ethics and accountability: from the for-itself to the for-the-other. Accounting, Organizations and Society, 27(6), 541-573.

Sinclair, A. (1995). The chameleon of accountability: forms and discourses. Accounting, Organizations and Society, 20(2), 219-237.

Steinbauer, R., Renn, R. W., Taylor, R. R., \& Njoroge, P. K. (2014). Ethical leadership and followers' moral judgment: The role of followers' perceived accountability and selfleadership. Journal of Business Ethics, 120(3), 381-392.

Tenbensel, T., Dwyer, J., \& Lavoie, J. (2014). How not to kill the golden goose: Reconceptualizing accountability environments of third-sector organizations. Public Management Review, 16(7), 925-944. doi: 10.1080/14719037.2013.770054

The World Bank. (2011). Accountability in public services in South Africa. Retrieved from http://siteresources.worldbank.org/INTSOUTHAFRICA/Resources/Accountability_in_ Public_Services_in_Africa.pdf.

Thoms, P., Dose, J. J., \& Scott, K. S. (2002). Relationships between accountability, job satisfaction, and trust. Human Resource Development Quarterly, 13(3), 307-323. 
Turusbekova, N., Broekhuis, M., Emans, B., \& Molleman, E. (2007). The role of individual accountability in promoting quality management systems. Total Quality Management, 18(5), 471-482. doi: 10.1080/14783360701239917

Wikhamn, W., \& T. Hall, A. (2014). Accountability and satisfaction: organizational support as a moderator. Journal of Managerial Psychology, 29(5), 458-471.

Willems, T., \& Van Dooren, W. (2011). Lost in diffusion? How collaborative arrangements lead to an accountability paradox. International Review of Administrative Sciences, 77(3), 505-530.

World Economic Forum. (2016). Global Competitiveness Report. retrieved from http://www3.weforum.org/docs/gcr/20152016/Global_Competitiveness_Report_2015-2016.pdf.

Zelnik, M., Maletič, M., Maletič, D., \& Gomišček, B. (2012). Quality management systems as a link between management and employees. Total Quality Management \& Business Excellence, 23(1), 45-62. doi: 10.1080/147833

Zikmund, W., Babin, B., Carr, J., \& Griffin, M. (2013). Business research methods. USA, South Western: Cengage Learning. 